possible to reclaim expenses through this. However, none of the patients in our group had insurance, which is unsurprising as they were probably unwell at the time of booking their flights and were unlikely to think of it. Second, patients would have to be fit to travel, or sufficiently supervised to make this feasible. Given that a high proportion may be significantly disturbed, this could again be expensive.

\section{References}

Daly, I.. WebB, M. \& Kaluszer, M. (1996) First admission incidence study of mania, 1975-1981. British Journal of Psychiatry, 167, 463-468.

JAUHAR, P. \& WELLER, M. P. I. (1982) Psychiatric morbidity and time zone changes: a study of patients from Heathrow Airport. British Journal of Psychiatry. 140. 231-235.
O'Hare, A., Whelan, C. T. \& Commins, P. (1991) The development of an Irish census-based social class scale. Economic and Social Review, 22, 135-156.

SHAPIRO, S. (1976) A study of psychiatric syndromes manifested at an international airport. Comprehensive Psychiatry. 17, 453-456.

WORID Health ORGanization (1978) Mental Disorders. Glossary and Guide to their Classification in Accordance with the Ninth Revision of the International Classification of Diseases (ICD-9). Geneva: WHO.

*C. Maher, Clinical Fellow, Clarke Institute of Psychiatry Toronto, Ontario and D. Murray, Consultant Psychiatrist, St Ita's Hospital, Portrane, County Dublin. Ireland

*Correspondence

\title{
Implications of urban drift on health care resources in inner London
}

\author{
A. J. Montgomery and A. M. Parshall
}

\begin{abstract}
All 34 patients admilted from a central area of London over a 10-week period were identitied. The 25 (73\%) who were subsequently interviewed were questioned about their whereabouts of various points in the past. Eleven (44\%) of the interviewed patients had artived in the area within one month prior to admistion, nine (36\%) within the last week. Seven (28\%) of the total were identified as not being the responsibility of the local authority. Patients who have recently aritved provide a significant proportion of the clinical workload in this area.
\end{abstract}

London mental health services are in crisis (Marshall, 1997). The King's Fund (1997) has described the problems faced by London's services and identified a number of inadequacies in service provision. Current methods of assessing the degree of capitation weighting fail to fully reflect the extra challenges that such services face (Goldberg, 1997). The contribution that homelessness makes to service requirements has already been highlighted (Turner \& Haskins, 1993). The extra burden of "geographical drift" (Gerard \& Houston, 1953) of mentally ill people to city centres is not taken into account in the current method of capitation weighting.

Although work in Sweden (Lewis et al, 1992) has cast doubt on the validity of the theory of drift to explain the excess prevalence of schizophrenia in urban environments, analysis of census data in Hampstead (McNaught et al, 1997) suggests that some of the excess is due to increased movements of individuals with schizophrenia, in particular, young men with positive symptoms. Clinical experience indicates that a significant proportion of patients admitted from the South Marylebone (North-East Westminster South (NEWS)) catchment area have 
Table 1. Location of study patients

\begin{tabular}{llll}
\hline & $\begin{array}{l}\text { The } \\
\text { Gordon }\end{array}$ & $\begin{array}{l}\text { Other } \\
\text { NHS }\end{array}$ & $\begin{array}{l}\text { Pivate } \\
\text { sector }\end{array}$ \\
\hline Interviewed & 18 & 1 & 6 \\
Not interviewed & 3 & 3 & 3 \\
\hline
\end{tabular}

recently arrived. Some of these may be so-called "psychiatric tourists" (Tannock \& Turner, 1995). The implications of issuing "psychiatric passports" by providing treatment and aftercare to such patients has already been noted by Parshall (1995).

Current National Health Service policy is for patients with a permanent address to be funded by their local health authority. For those that have recently moved into an area, the threemonth rule' sometimes still applies, whereby the new health authority takes over responsibility after three months. For those with no fixed abode the area from which the patient is admitted (often the street from which the patient is found or picked up) assumes responsibility. In cases of dispute the final arbiter can be where the patient says he or she lives. With the acute pressure on psychiatric beds, at least in the inner city, the three-month rule is apparently no longer supported on all occasions. Some services insist on a six-month handover period, while others maintain that in-patient and continuing care responsibility resides with the locality from the day the individual is housed or 'picked-up' there.

South Marylebone (NEWS) encompasses such diverse areas as Soho, Mayfair and Marylebone. It is, on average, a moderately deprived area with Jarman indices between 17.22 and 24.35. It has a large homeless population as well as a huge number of tourists visiting every year. The resident population is 33000 . The area has a relatively large number of direct access hostels and this may account, in part, for its attractiveness to insecurely housed individuals who are thought to suffer from higher than average rates of mental illness. In-patient beds are at the Gordon Hospital, where 14 beds out of a total of 64 are allocated to the South Marylebone (NEWS) sector. Bed occupancy is on average $130 \%$.
We surveyed the movements prior to admission of all patients admitted over a 10week period (4 September 1996-22 November 1996) with the aim of establishing the proportion of patients that had recently arrived in the area.

\section{The study}

The names and current location of all patients admitted from the above area were obtained from the bed-manager at the local admitting hospital (the Gordon). All patients who could be traced and were prepared to be interviewed were seen by one of the investigators (A.M.) who applied a short semi-structured questionnaire. This included socio-demographic details and questions about the whereabouts of the patient at various fixed points in the past, from the place of birth to the night prior to admission.

The locations were coded into four categories: South Marylebone (NEWS); London, outside South Marylebone (NEWS); outside London, in the United Kingdom; and outside the United Kingdom (including Eire).

The total number of patients admitted over a period of one year, including the study period, was estimated from data collected by the bedmanager. For all patients interviewed, the health authority assuming responsibility was identified.

\section{Findings}

A total of 34 patients were identified over the 10week period. This compared to an annual admission rate of 147 from April 1996 to March 1997. Twenty-five of the 34 were successfully traced and interviewed, of the remainder, three declined to be interviewed, three were judged by nursing and medical staff to be too ill to be seen. two were discharged before they could be seen and one could not be identified at the hospital he was transferred to.

Table 1 shows the location of patients at the time of assessment divided into interviewed and uninterviewed groups.

The average age of the 14 males was 37 (range: 20 to 61 ) and of the 11 females also 37 (range: 20 to 84). Sixteen of the total were unemployed and seven were homeless (including two street homeless and five in hostels or other insecure

Table 2. Locations of patients at fixed points in the past

\begin{tabular}{llllllll}
\hline \multicolumn{7}{l}{ Time prior to admission } \\
\cline { 2 - 7 } Location & Last night & One week One month & One year Five years 10 years Birth \\
\hline South Marylebone (NEWS) & $20(80 \%)$ & $16(64 \%)$ & $14(56 \%)$ & $11(44 \%)$ & $9(36 \%)$ & $4(16 \%)$ & 0 \\
London, outside South Marylebone & $3(12 \%)$ & $5(20 \%)$ & $5(20 \%)$ & $3(12 \%)$ & $4(16 \%)$ & $5(20 \%)$ & $7(28 \%)$ \\
Outside London, in the UK & $2(8 \%)$ & $2(8 \%)$ & $2(8 \%)$ & $3(12 \%)$ & $3(12 \%)$ & $4(16 \%)$ & $3(12 \%)$ \\
Outside the UK & 0 & $1(4 \%)$ & $2(8 \%)$ & $4(16 \%)$ & $6(24 \%)$ & $7(28 \%)$ & $13(52 \%)$ \\
Location unknown & 0 & $1(4 \%)$ & $2(8 \%)$ & $4(16 \%)$ & $3(12 \%)$ & $5(20 \%)$ & $2(8 \%)$ \\
\hline
\end{tabular}


accommodation). The location data are shown in Table 2.

Three patients were identified as falling under the responsibility of other authorities and were either admitted directly to local units or transferred within a few days of admission. Four patients were identified as overseas visitors and funding was sought from the Home Office. Thus, only $14(56 \%)$ of the patients were resident in the area, or indeed in the area at all, one month prior to admission. Even as recently as one week prior to admission nine $(36 \%)$ of the patients were not resident or in the local area. Two $(8 \%)$ of the patients had arrived from abroad within the last month. None of the patients were born in the area.

\section{Comments}

In the present survey we have obtained detailed information about a relatively small number of patients. This contrasts with other work in the area which has relied on census and other national surveys with large numbers of subjects but necessarily limited detail. A limitation of this survey is its reliance on accurate reporting by patients. Care was taken to avoid pressurising patients into committing themselves when they were uncertain, but no corroborative evidence was available to confirm their reports.

The current system of resource allocation is based on a study by Carr-Hill et al (1994). In this study a large number of variables derived from a variety of sources including the 1991 census, were assessed for their association to current health care provision, as a way of predicting future resource allocation. The parsimonious model they derived did not include a mobility factor because it was not found to be closely linked with health care provision on a national level. Nevertheless, we have shown that on a local level migration is a significant factor, and certain areas, such as the one studied, are significantly impacted upon in terms of resource use by migration. Carr-Hill et al make the recommendation that "a system for adjusting allocation to districts in the light of local circumstances is retained".

It is of note that a significant proportion of the patients identified in the study as recent arrivals from other areas (i.e. in the locality for one month or less) were neither funded as extra-contractual referrals nor returned to their local unit.

\section{Discussion}

This survey confirms that recent arrivals make up a significant proportion of patients admitted from this area of central London. Some of these patients are not being identified by the local authority and are consequently funded locally.

We propose that there should be clarification of the responsibilities of authorities to fund migrating patients. Patients could be classified according to their origin in terms of, for example, the four categories used in this paper. This would be of value to the authority with responsibility for admitting and discharging patients by allowing the construction of a dataset giving an indication of the local significance of migration.

Second, local allocation of resources should reflect the extra demands made by new arrivals. Without this, magnification of the inadequacy of inner-city funding already identifled will result. In this service increased costs could be as much as $20 \%$ which local efficiency savings will be unable to match.

The data supports the view that there may be enduring and accumulating resource issues for areas at the receiving end of 'urban drift'.

\section{Acknowledgements}

We thank Alistair Robinson, Bed manager, and Sian Hopkinson, Information Manager, at the Gordon Hospital, for their assistance, without which this survey would not have been possible.

\section{References}

CARR-Hill, R. A., HARDMAN, G., MARTIN, S., et al (1994) A Formula for Distributing NHS Revenues Based on Small Area Use of Hospital Beds. York: Centre of Health Economics. University of York.

GolDBERG, D. (1997) London's Mental Health Services. Psychiatric Bulletin, 21, 65-66.

Gerard, D. L. \& Houston, L. G. (1953) Family setting and the urban distribution of schizophrenia. Psychiatric Quarterly, 27, 19-37.

KING'S Fund (1997) London's Mental Health. London: King's Fund.

LewIS, G., DAvid, A., ANDreasson, S., et al (1992) Schizophrenia and city life. Lancet, 340, 137-139.

MARSHALL, M. (1997) London's mental health services in crisis. British Medical Journal, 314, 246.

MCNAUGHT, A. S., JeFFREYS, C. A., HARVEY, C. A., et al (1997) The Hampstead Schizophrenia Survey 1991. II: Incidence and migration in inner London. British Journal of Psychiatry, 170, 307-311.

PARShall, A. (1995) Psychiatric tourism. a real phenomenon. British Medical Journal, 311, 1567.

TURNER, S. \& HASKINS, C. (1993) London capitation weighting: social deprivation, homelessness and mental health. Psychiatric Bulletin. 17, 641-646.

TANNOCK. C. \& TURNER, S. (1995) Psychiatric tourism is overloading London beds. British Medical Journal, 311. 806.

*A. J. Montgomery, Senior House Officer in Psychiatry, Department of Psychiatry, Charing Cross Hospital, Fulham Palace Road, London W6 8RP and A. M. Parshall, Consultant Psychiatrist, Gordon Hospital, London

*Correspondence 